\title{
Profile distribution of soil-water content and its temporal stability along a 1340-m long transect on the Loess Plateau, China
}

\author{
Xuezhang Li ${ }^{\mathrm{a}, \mathrm{b}, \mathrm{c}}$, Ming'an Shao ${ }^{\mathrm{c}, *}$, Xiaoxu Jia ${ }^{\mathrm{c}}$, Xiaorong Wei ${ }^{\mathrm{d}}$ \\ a Key Laboratory for Agro-ecological Processes in Subtropical Region, Institute of Subtropical Agriculture, Chinese Academy of Sciences, Changsha 410125, China \\ ${ }^{\mathrm{b}}$ Huanjiang Observation and Research Station for Karst Ecosystem. Chinese Academy of Sciences, Huanjiang 547100. China \\ c Key Laboratory of Ecosystem Network Observation and Modeling, Institute of Geographic Sciences and Natural Resources Research, Chinese Academy of Sciences, Beijing 100101, China \\ d State Key Laboratory of Soil Erosion and Dryland Farming on the Loess Plateau, Northwest A E F University, Yangling 712100, China
}

\section{A R T I C L E I N F O}

\section{Article history:}

Received 10 November 2014

Received in revised form 6 September 2015

Accepted 7 September 2015

Available online 19 September 2015

\section{Keywords:}

Temporal stability

Profile distribution

Soil-water content

Representative location

Semi-arid area

\begin{abstract}
A B S T R A C T
Information on the profile characteristics of soil-water content (SWC) and its temporal stability is essential for an accurate understanding of hydrological processes. This study investigated changes of spatial variation and temporal stability of SWC in soil profiles and estimated mean SWC based on direct and indirect methods. SWCs were measured at 20 - $\mathrm{cm}$ intervals in the soil profiles to a depth of $3 \mathrm{~m}$ using neutron probes at 135 locations along a 1340-m long transect on 18 sampling dates from 2012 to 2013 on the Loess Plateau in China. The coefficient of variation over space $\left(\mathrm{CV}_{\mathrm{S}}\right)$ of SWC first decreased and then increased vertically. The coefficient of variation over time $\left(\mathrm{CV}_{\mathrm{T}}\right)$ of $\mathrm{SWC}$ decreased along the soil profiles. The spatial patterns of SWC strongly persisted vertically and temporally. Mean Spearman's rank correlation coefficients decreased from a depth of 10 to a depth of $20 \mathrm{~cm}$, fluctuated from 20 to $180 \mathrm{~cm}$, and then increased below $200 \mathrm{~cm}$. Temporal stability increased along the soil profiles based on the standard deviation of mean relative difference (SDRD) and the mean absolute bias error (MABE). The number of locations with an SDRD and/or MABE $<5 \%$ increased along the soil profile, and the number of locations with a mean relative difference within $\pm 5 \%$ and/or representative locations were variably dependent on depth. Both direct and indirect methods could accurately estimate the mean SWC for each depth based on the mean absolute relative errors and root mean square errors. The driest and wettest locations tended to remain representative for more depths than did locations with mean-moistures. The driest locations were more likely to be the most temporally stable. These findings should improve our understanding of soil-water dynamics in soil profiles.
\end{abstract}

(c) 2015 Published by Elsevier B.V.

\section{Introduction}

Soil-water content (SWC) is broadly acknowledged as an important control of many geomorphic and hydrological processes (Penna et al., 2013). It is also the principal limiting factor for vegetational restoration (Hu et al., 2009) and agricultural production (Tallon and Si, 2004) in semi-arid and arid regions. SWC can regulate the subsurface flow and migration of pollutants and chemicals to environmentally sensitive areas (Biswas and Si, 2011a). Less is known about deep layers than about surface SWC due to the difficulty of acquiring data. The relationships of SWC at different depths are also unclear. Obtaining information on soil-water dynamics at various depths is thus necessary.

SWC is variable in both space and time across different scales (Manfreda and Rodriguez-Iturbe, 2006; Famiglietti et al., 2008). The characteristics of the spatial variability of SWC have been widely studied in various ecosystems and at various scales (Wang et al., 2013). Despite the variability of SWC, repeated surveys can often identify certain sites,

\footnotetext{
* Corresponding author.

E-mail address: shaoma@igsnrr.ac.cn (M. Shao).
}

which are relatively stable over time and can be served as representative locations for an area of interest. The concept of temporal stability of spatial patterns of SWC was first introduced by Vachaud et al. (1985), who defined it as "the time-invariant association between spatial location and classical statistical parameters of a given soil property". The temporal stability of SWC has been investigated for different soil depths (Zhang and Shao, 2013; Heathman, 2009), land uses (Hu et al., 2010a; Williams et al., 2009; Lin, 2006), scales (Martínez-Fernández and Ceballos, 2003; Jia and Shao, 2013; Hu et al., 2010b; Gao et al., 2011), regions (Biswas and Si, 2011b; Jia et al., 2013a; Zhang and Shao, 2013), measurement periods (Guber et al., 2008; de Rosnay, et al., 2009; Zhao, et al., 2010; Biswas and Si, 2011b; Liu and Shao, 2014), and measuring instruments (Jacobs et al., 2004; Gao and Shao, 2012b; Wang et al., 2013; Penna et al., 2013). The characteristics of the temporal stability of SWC vary with depth, but little is known about the precise changes of SWC and its temporal stability in soil profiles due to coarse division of previous soil profiling. Furthermore, the findings of some studies conflict. For example, Gao and Shao (2012a) reported that the temporal stability of soil-water storage increased with depths at $0-1,1-2$, and $2-3 \mathrm{~m}$. In contrast, Hu et al. (2009) 
observed that the temporal stability of SWC was greater at $0.2 \mathrm{~m}$ than at $0.4,0.6$, and $0.8 \mathrm{~m}$. Differences in depth of sampling may thus have an impact on the determination of temporal stability and may lead to conflicting information. Precise changes of SWC and its temporal stability may be observed by carefully sectioning the soil profile. In the present study, soil profiles were sampled at $20-\mathrm{cm}$ intervals for capturing the characteristics of temporal stability.

Some studies have proposed that mean SWC can be estimated directly by identifying representative locations based on certain principles (Hu et al., 2010a; Gao and Shao, 2012a; Jia et al., 2013a), which may not always apply. As a consequence, many studies have investigated alternative approaches by attempting to find representative locations using other properties that can affect SWC, but the identification of representative locations remains inconsistent. For example, da Silva et al. (2001) observed that organic-carbon and clay contents could serve as better explanatory variables than topographic variables. In contrast, Gómez-Plaza et al. (2000) found that vegetation and topography rather than soil properties were more likely to be the primary factors affecting the temporal stability of SWC. Jacobs et al. (2004) concluded that sampling locations with intermediate to moderately high clay contents tended to generate the most temporal stability, and Mohanty and Skaggs (2001) reported that sandy loam had better temporal stability than silty loam. Liu and Shao (2014) found that many of the most temporally stable locations were near the centres of the plots established on a hillslope, and Tallon and Si (2004) observed that temporally stable locations had weak relationships with topographic properties. Grayson and Western (1998) thus proposed an indirect method by introducing a constant offset. This method has been used in other studies (Gao et al., 2011; Wang et al., 2013), but the accuracy of prediction of both the direct and indirect methods along soil profiles is unknown and requires evaluation.

The temporal stability of SWC relies on many factors such as soil properties, vegetation, and topography (Vachaud et al., 1985; Hu et al., 2010b; Zhao et al., 2010; Jia et al., 2013a; Jia and Shao, 2013). Temporal stability is also associated with the status of the SWC (MartínezFernández and Ceballos, 2003; Gao and Shao, 2012a; Jia et al., 2013b). Considerable debate, however, remains about the effect of SWC status on temporal stability. Martínez-Fernández and Ceballos (2003) found that the temporal stability of SWC was more pronounced under dry than under wet conditions. In contrast, Gómez-Plaza et al. (2000) observed that SWC was less stable during dry periods than during humid periods when the vegetation consumed more water. Gao et al. (2011) indicated that SWC was not very temporally stable during the transition period from dry to wet. Furthermore, little attention has been focused on the changes at locations representing different soil-moisture conditions along soil profiles. The ability of single locations to represent several soil depths with different moisture status is unknown. Confirmation of the dependence of the characteristics of temporal stability on soil-moisture conditions is thus necessary.

We analysed the characteristics of SWC and its temporal stability at 15 depths along a transect on the Loess Plateau, China, to: (1) assess the depth persistence of spatial patterns of SWC within the soil profiles, (2) describe the precise changes of temporal stability of SWC along the profiles, (3) evaluate both the direct and indirect methods for estimating mean SWC at different depths, and (4) investigate the relationships between temporal stability and sampling location under different soil-moisture conditions.

\section{Materials and methods}

\subsection{Study area and experimental design}

The experiment was conducted in the Liudaogou catchment $\left(110^{\circ} 21^{\prime}-110^{\circ} 23^{\prime} \mathrm{E}\right.$ and $\left.38^{\circ} 46^{\prime}-38^{\circ} 51^{\prime} \mathrm{N}\right)$ of Shenmu County in Shaanxi Province, China (Fig. 1). The study area is in a transitional belt with severe soil and wind erosion. The Liudaogou catchment has an area of
$6.89 \mathrm{~km}^{2}$ and is characterised by deep gullies and undulating loessial slopes. The elevation ranges from 1056 to $1130 \mathrm{~m}$ a.s.l. The area has a semi-arid continental climate with a mean annual temperature of $8.4{ }^{\circ} \mathrm{C}$ and a mean annual precipitation of $437 \mathrm{~mm}$, more than $70 \%$ of which falls from June to September. The predominant plants are purple alfalfa (Medicago sativa L.), Korshinsk Peashrub (Caragana korshinskii K.), and bunge needlegrass (Stipa bungeana T.). The soils are classified as aeolian sandy soils and Ust-Sandiic Entisol soils (Hu et al., 2010b).

A transect containing 135 sampling locations was selected in July 2012 based on soil type, landform, and vegetation. Among the 135 sampling locations, 126 and 9 were located on hillslopes and in gullies, respectively. The vegetation along the transect included purple alfalfa, Korshinsk Peashrubs, and bunge needlegrass with 10, 52, and 53 locations, respectively, and 20 locations contained bare land. The sampling transect was approximately $1340 \mathrm{~m}$ long with a regular sampling interval of $10 \mathrm{~m}$ (Fig. 1). An aluminium neutron-probe access tube $3.3 \mathrm{~m}$ in length was installed using an auger at each location for SWC measurement at 15 soil depths.

\subsection{Measurement of SWC}

The mean volumetric soil-water contents (SWCs) at intervals of $20 \mathrm{~cm}$ from depths of 0.2 to $3.0 \mathrm{~m}$ as well as at $10 \mathrm{~cm}$ depth were measured on 18 sampling occasions from 23 August 2012 to 28 October 2013. Volumetric SWCs were measured with a neutron moisture metre, the CNC 503DR Hydro probe (Beijing Super Power Company, Beijing, China) with standard count of 685. Gravimetric SWCs were also determined at 12 selected sampling locations for calibrating the neutron probes. These calibrations were conducted three times during the sampling period (April, June, and October 2013) under different soil-water conditions. These 12 locations were selected because the mean and range of the neutron counting data approximated those of all tubes along the transect (Hu et al., 2010b; Liu and Shao, 2014). They also represented the principal soils, landforms, and vegetation. A pit $1 \mathrm{~m}$ deep was excavated at each location for the collection of undisturbed core samples $\left(100 \mathrm{~cm}^{3}\right)$ at 10 depths for determining bulk density. A total of 360 paired data points for bulk density and gravimetric SWCs were obtained for calculating the corresponding volumetric water contents for the three calibrations. A linear calibration curve was thereby established:

$\theta=0.6565 C R-0.0068\left(R^{2}=0.9031, P<0.001\right)$

where $\theta$ is the volumetric SWC $\left(\mathrm{cm}^{3} \mathrm{~cm}^{-3}\right)$ and $C R$ is the slow-neutron counting rate.

\subsection{Assessment of the temporal stability of SWC}

Three methods were used to evaluate the temporal stability of SWC. The first method was based on relative difference initially introduced by Vachaud et al. (1985). The relative difference at location $i$ at depth $k$ for sampling time $j$ is calculated as:

$\delta_{i j k}=\frac{\theta_{i j k}-\overline{\theta_{j k}}}{\overline{\theta_{j k}}}$.

The temporal mean relative difference (MRD) and its standard deviation (SDRD) for each sampling location are expressed as:

$\overline{\delta_{i k}}=\frac{1}{M} \sum_{j=1}^{M} \delta_{i j k}$

and

$\sigma\left(\delta_{i k}\right)=\sqrt{\frac{1}{M-1} \sum_{j=1}^{M}\left(\delta_{i j k}-\overline{\delta_{i k}}\right)^{2}}$ 


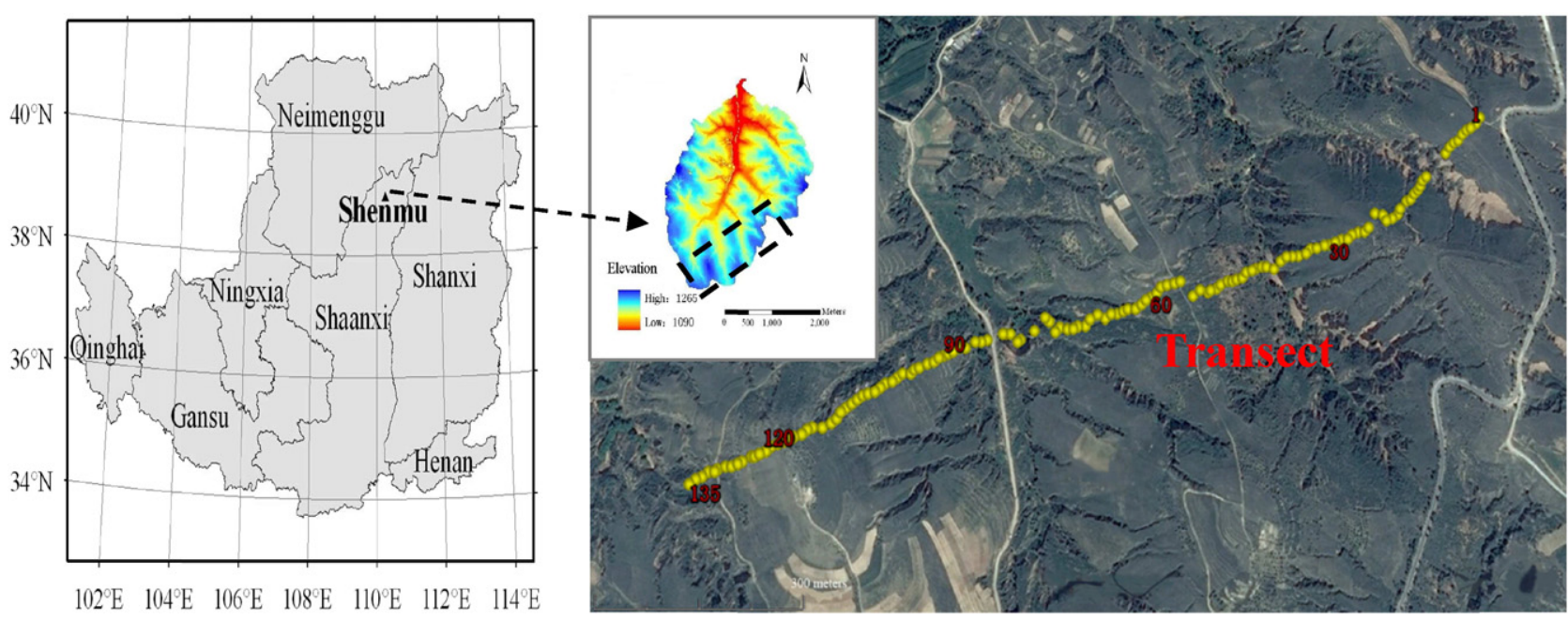

Fig. 1. Location of study site and transect position in the Liudaogou catchment in northwestern China.

where $\theta_{i j k}$ is the SWC at location $i$ and depth $k$ for sampling time $j, \bar{\theta}_{j k}$ is the areal mean SWC at depth $k$ at time $j$ for all sampling locations, and M is the number of measurement campaigns at each sampling location. The value of the MRD determined whether a location was wetter or drier than the areal mean SWC at a particular depth, and a lower SDRD at a sampling location indicated a higher temporal stability.

In the second method, Hu et al. (2010a) proposed a new index of mean absolute bias error (MABE). Rearranging Eq. (2), the mean SWC at depth $k$ of measurement campaign $j$ can be calculated as:

$\overline{\theta_{j k}}=\frac{\theta_{i j k}}{1+\delta_{i j k}}$.

Assuming a constant offset $\overline{\delta_{i k}}$ for a temporally stable location, the estimated mean $\theta, \overline{\theta_{j k}}$, can be expressed as (Grayson and Western, 1998):

${\overrightarrow{\theta_{j k}}}^{\prime}=\frac{\theta_{i j k}}{1+\overline{\delta_{i k}}}$.

The bias error of mean $\theta, \varphi_{i j k}$, can thus be written as:

$\varphi_{i j k}=\frac{\overline{\theta_{j k}}-\overline{\theta_{j k}}}{\overline{\theta_{j k}}}$

substituting Eqs. (5) and (6) in Eq. (7):

$\varphi_{i j k}=\frac{\delta_{i j k}-\overline{\delta_{i k}}}{1+\overline{\delta_{i k}}}$.

The absolute bias error ( $A B E)$ and the mean absolute bias error (MABE) can be defined as:

$A B E_{i k}=\left|\frac{\delta_{i j k}-\overline{\delta_{i k}}}{1+\overline{\delta_{i k}}}\right|$

and

$M A B E_{i k}=\frac{1}{N} \sum_{j=1}^{N}\left|\frac{\delta_{i j k}-\overline{\delta_{i k}}}{1+\overline{\delta_{i k}}}\right|$.

Similar to the SDRD index, a lower MABE at a location corresponds to a higher temporal stability of SWC.
The non-parametric Spearman's test was also used to examine the persistence of the spatial patterns over the study period (Vachaud et al., 1985). The Spearman's rank correlation coefficient $\left(r_{s}\right)$ is expressed as:

$r_{s}=1-\frac{6 \sum_{i=1}^{N}\left(R_{i j}-R_{i j^{\prime}}\right)^{2}}{N\left(N^{2}-1\right)}$

where $R_{i j}$ is the rank of the variable $\theta_{i j}$ at location $i$ and time $j, \mathrm{R}_{\mathrm{ij}}$ is the rank of the same variable at the same location but at time $j^{\prime}$, and $\mathrm{N}$ is the number of observation sites. An $r_{s}$ equal to 1 between measurement campaigns indicates a strong tendency of temporal stability.

\subsection{Estimation of the spatial mean SWC}

A useful application of temporal stability is to evaluate the soilwater status of an area of interest using representative locations. Locations with both an MRD closest to zero and the smallest SDRD can be used directly to estimate the mean SWC (Martínez-Fernández and Ceballos, 2005). For example, Gao and Shao (2012a) defined representative locations with an allowable bias of $5 \%$ for both MRD and SDRD for greater accuracy of prediction. No single location, however, is likely to meet the above two conditions simultaneously for a specific depth. Alternatively, the most temporally stable locations with non-zero MRDs can be used to calculate the mean SWC (Grayson and Western, $1998)$. The relative difference on any sampling campaign $\left(\delta_{i j k}\right)$ is approximately equal to the mean relative difference $\left(\delta_{i k}\right)$, so the spatial mean SWC at depth $k$ for time $j$ can be indirectly calculated using Eq. (6).

We used two criteria to measure the strength of the statistical relationship between the predicted and measured values: the mean absolute relative error (MARE) and the root mean square error (RMSE). MARE is calculated as:

$M A R E=\frac{1}{q} \sum_{j=1}^{q} \frac{\left|\overline{S W C_{j k}^{\prime}}-\overline{S W C_{j k}}\right|}{\overline{S W C_{j k}}}$

where $q$ is the number of sampling dates, $\overline{S W C_{j k}}$ is the measured SWC at the most temporally stable location $i$ and the same depth $k$, and $\overline{S W C_{j k}^{\prime}}$ is the predicted SWC at depth $k$ for time $j$. The accuracy of prediction is acceptable at a MARE $<0.1 \%$ (Peterson and Wicks, 2006; Hu et al., 2009). RMSE is calculated as:

$R M S E=\sqrt{\frac{1}{N} \sum_{i=1}^{N}\left(P_{i}-p_{i}\right)^{2}}$ 


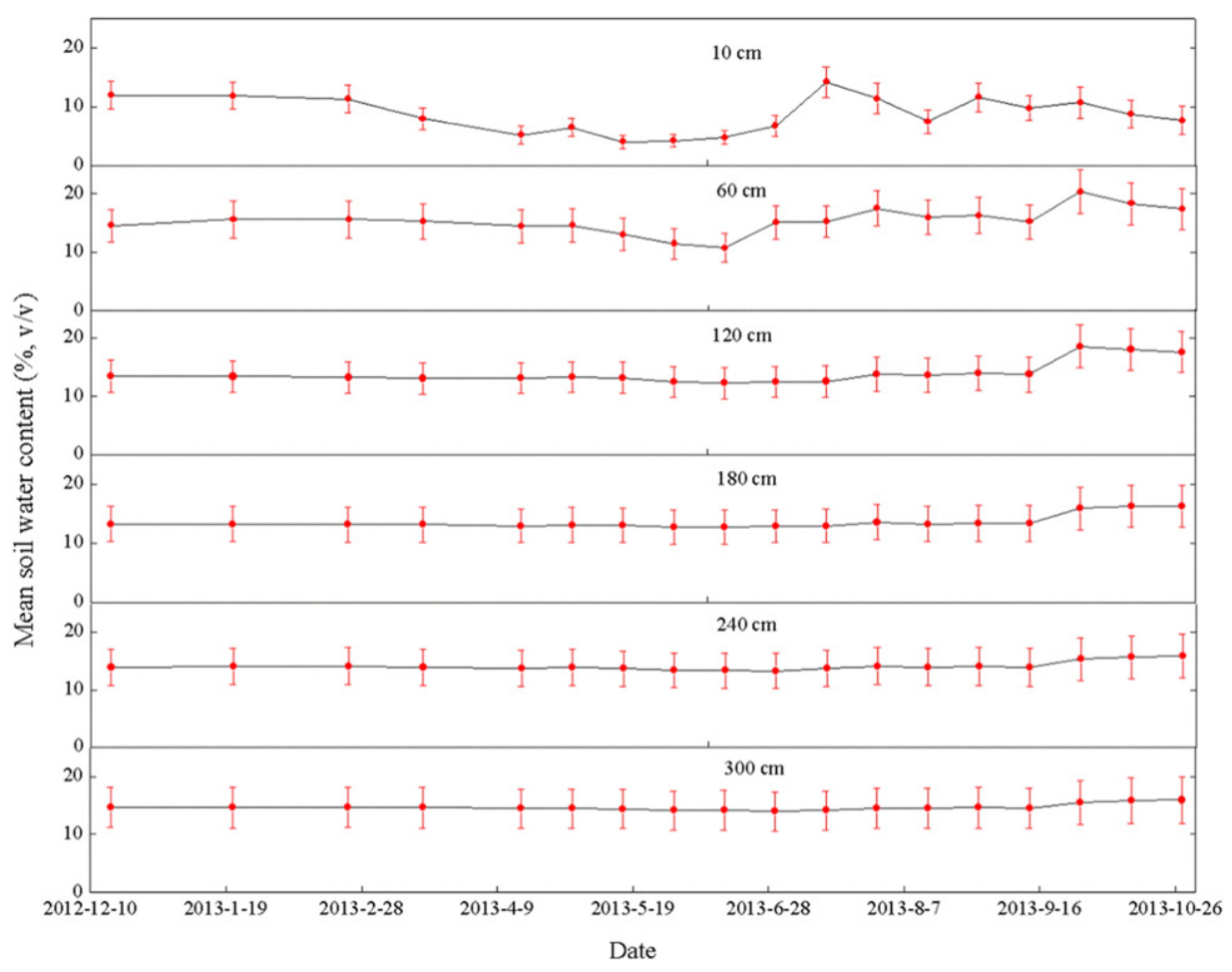

Fig. 2. Time series of spatial mean soil-water content for various soil depths of the transect.

where $P_{i}$ and $p_{i}$ are the predicted and measured values, respectively. The accuracy of prediction is reliable at an RMSE $<2 \%$ (Cosh et al., 2008).

\subsection{Statistical analysis}

Exploratory data analysis was performed using Microsoft Excel. Pearson correlation analysis was used to characterise the relationship of SWC among the various depths. One-way analyses of variance were used to test the significance of the differences in SWC and the criteria of temporal stability among the various depths. Linear-fitting analysis was conducted between the observed and estimated mean SWCs using the MARE and RMSE as measures of goodness-of-fit. The statistical analyses of the SWC data were performed with SPSS 16.0.

\section{Results and discussion}

\subsection{Temporal-spatial dynamics of SWC within the soil profile}

The temporal evolution of spatial mean SWC for six selected soil depths is presented in Fig. 2. The spatial mean SWCs over time were

Table 1

Temporal-spatial statistics of mean soil-water content (SWC) for various soil depths.

\begin{tabular}{llrrrrrr}
\hline Variables & Parameter & $10 \mathrm{~cm}$ & $60 \mathrm{~cm}$ & $120 \mathrm{~cm}$ & $180 \mathrm{~cm}$ & $240 \mathrm{~cm}$ & $300 \mathrm{~cm}$ \\
\hline \multirow{5}{*}{ Spatial SWC } & Mean, \% & $8.72 \mathrm{a}^{\S}$ & $15.40 \mathrm{c}$ & $13.96 \mathrm{~b}$ & $13.63 \mathrm{~b}$ & $14.09 \mathrm{~b}$ & $14.68 \mathrm{bc}$ \\
& Max, \% & 14.23 & 20.38 & 18.51 & 16.30 & 15.85 & 15.95 \\
& Min, \% & 4.10 & 10.79 & 12.25 & 12.74 & 13.28 & 14.02 \\
& $\mathrm{SD}_{\mathrm{T}}, \%$ & 3.06 & 2.27 & 1.93 & 1.18 & 0.74 & 0.55 \\
& $\mathrm{CV}_{\mathrm{T}}, \%$ & 35.10 & 14.74 & 13.85 & 8.62 & 5.28 & 3.74 \\
& Max, \% & 21.96 & 30.18 & 32.96 & 35.12 & 37.95 & 41.56 \\
Temporal SWC & Min, \% & 2.01 & 4.98 & 4.82 & 3.46 & 2.91 & 2.89 \\
& $\mathrm{SD}_{\mathrm{S}}, \%$ & 3.74 & 5.82 & 5.61 & 5.93 & 6.40 & 6.94 \\
& $\mathrm{CV}_{\mathrm{S}}, \%$ & 42.95 & 37.79 & 40.16 & 43.53 & 45.43 & 47.29 \\
\hline
\end{tabular}

$\mathrm{SD}_{\mathrm{T}}$, standard deviation of time series of the mean spatial SWC; $\mathrm{CV}_{\mathrm{T}}$, coefficient of variation of time series of the mean spatial SWC; $\mathrm{SD}_{\mathrm{S}}$, standard deviation of the mean spatial SWC; $\mathrm{CV}_{\mathrm{S}}$, coefficient of variation of the mean spatial SWC.

$\S$ Different lowercase letters within a row indicate significant differences determined by Duncan's Multiple Range Test $(P<0.05)$.
8.7, 15.4, 14.0, 13.6, 14.1, and $14.7 \%$ at depths of 10, 60, 120, 180, 240, and $300 \mathrm{~cm}$, respectively. Spatial mean SWC was significantly lower $(P<0.05)$ at $10 \mathrm{~cm}$ and was significantly higher $(P<0.05)$ at $60 \mathrm{~cm}$ than at the other depths (Table 1$)$. Spatial mean SWC did not differ significantly $(P<0.05)$ among the $120,180,240$, and $300 \mathrm{~cm}$ depths. Gao and Shao (2012a), however, found no significant differences in soilwater storage among depths of $0-100,100-200$, and $200-300 \mathrm{~cm}$. The reason for the inconsistent results is probably that SWC is a function of variable properties such as soil texture, vegetation cover, topography and climate (Grayson et al., 1997; Tromp-van Meerveld and McDonnell, 2006; Lawrence and Hornberger, 2007; Garcia-Estringana et al., 2012), and SWC of the shallow soil $(0-60 \mathrm{~cm})$ is more affected by external conditions and vegetation.

The standard deviation and coefficient of variation over time $\left(\mathrm{SD}_{\mathrm{T}}\right.$ and $\mathrm{CV}_{\mathrm{T}}$ ) of SWC decreased with increasing depth (Fig. 4a). For example, $\mathrm{SD}_{\mathrm{T}}$ and $\mathrm{CV}_{\mathrm{T}}$ decreased from 3.06 and $35.10 \%$ at $10 \mathrm{~cm}$ to 0.55 and $3.74 \%$ at $300 \mathrm{~cm}$, respectively (Table 1 ). These results indicated that the temporal changes of SWC decreased with increasing depth, consistent with the findings by Choi and Jacobs (2007), Gao and Shao (2012a),

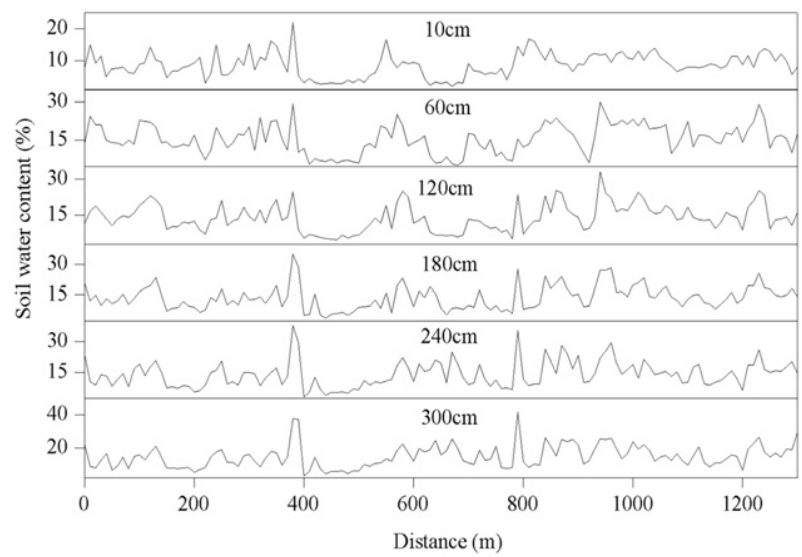

Fig. 3. Temporal mean soil-water content along the transect at various soil depths. 


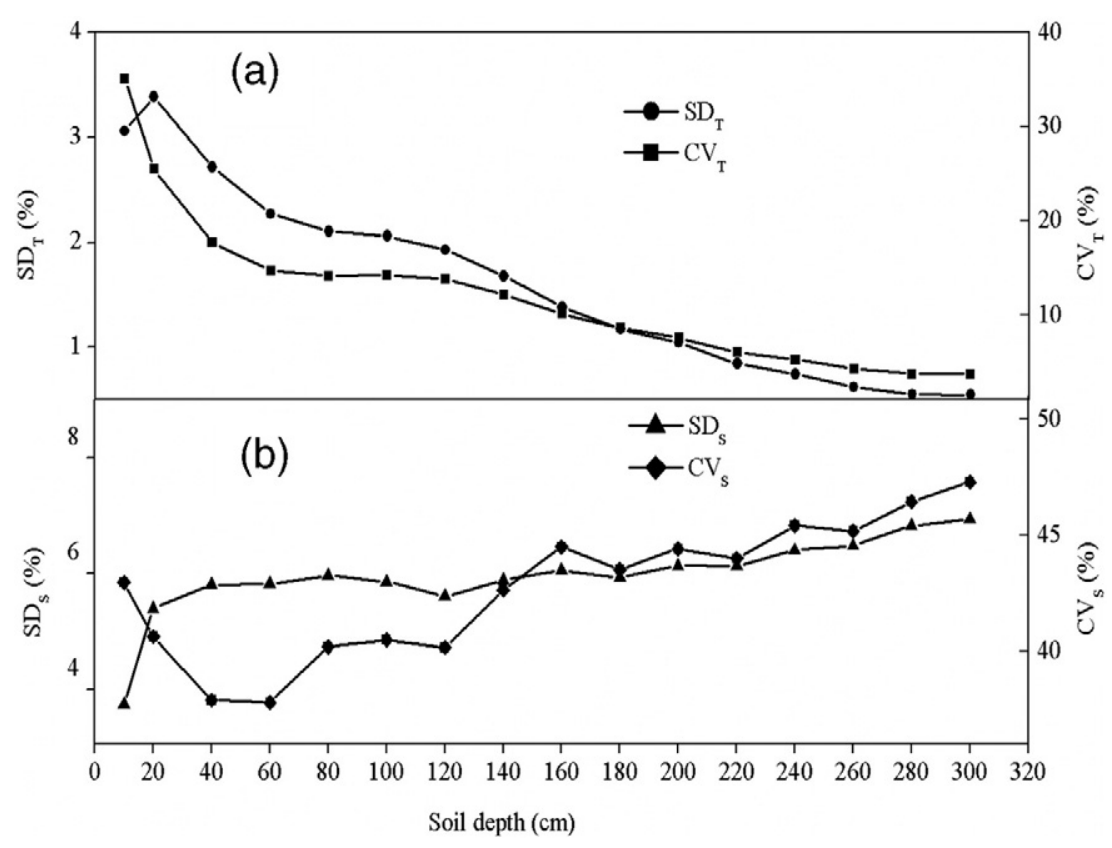

Fig. 4. Profile distribution of standard deviations $(\mathrm{SD})$ and coefficients of variation $(\mathrm{CV})$ of soil-water content $(\mathrm{a})$ over time $\left(\mathrm{SD}_{\mathrm{T}}\right.$ and $\left.\mathrm{CV}_{\mathrm{T}}\right)$ and $(\mathrm{b})$ over $\mathrm{Space}_{(\mathrm{SD}} \mathrm{S}$ and $\left.\mathrm{CV}_{\mathrm{S}}\right)$.

and Jia et al. (2013a). The standard deviation over space $\left(\mathrm{SD}_{\mathrm{S}}\right)$ increased from $3.74 \%$ at $10 \mathrm{~cm}$ to $6.94 \%$ at $300 \mathrm{~cm}$, and the coefficient of variation over space $\left(\mathrm{CV}_{\mathrm{S}}\right)$ decreased from $42.95 \%$ at $10 \mathrm{~cm}$ to $37.79 \%$ at $60 \mathrm{~cm}$ and then gradually increased to $47.29 \%$ at $300 \mathrm{~cm}$ (Table 1, Fig. 4b). The $\mathrm{CV}_{\mathrm{S}}$ were near $40 \%$, representing moderate variability (Nielsen and Bouma, 1985). The larger $\mathrm{CV}_{\mathrm{S}}$ at $10 \mathrm{~cm}$ was possibly related to the heterogeneity of solar radiation, landform and so on. The larger $\mathrm{CV}_{\mathrm{S}}$ in deeper depth, however, was probably due to the relatively high spatial variability of soil properties and root system (Li et al., 2015). In contrast with the upper depths, a higher $\mathrm{SD}_{\mathrm{S}}$ and $\mathrm{CV}_{\mathrm{S}}$ was generally found for the deeper depths, in agreement with the findings by other studies (De Lannoy et al., 2006; Gao and Shao, 2012a).

\subsection{Relationships of SWC among various soil depths within the soil profile}

The spatial patterns of SWC were similar among different soil depths (Fig. 3). Table 2 shows a matrix of Pearson correlation coefficients of SWC for various depths. The correlation coefficients between any two depths were statistically significant $(P<0.01)$, consistent with other findings in different study areas (Fernandez and Ceballos, 2005; Biswas and Si, 2011a; Choi and Jacobs, 2007, 2011; Heathman et al.,
2012). The significant similarity of SWC spatial patterns may be due to the vertical homogeneity in soil textural properties (Gao and Shao, 2012a) or to the similar vegetation and/or topographic features at the same location. For example, locations with trees always consumed more soil water than with grasses (Garcia-Estringana et al., 2012), and locations located in depressions contained more soil water than on knolls for each depth (Biswas and Si, 2011a).

The correlation coefficients decreased with the increasing distance between depths. For example, the correlation coefficient was 0.91 between the SWCs at 10 and $20 \mathrm{~cm}$ and was 0.29 between 10 and $300 \mathrm{~cm}$ (Table 2). Furthermore, the mean correlation coefficient gradually decreased from 0.957 for an interval of $20 \mathrm{~cm}$ to 0.346 for an interval of $280 \mathrm{~cm}$ (Fig. 5). Similar results have been reported (Tallon and Si, 2004; Guber et al., 2008; Hu et al., 2009; Biswas and Si, 2011a). Biswas and $\mathrm{Si}$ (2011a) reported a correlation coefficient of 0.84 between soilwater storages of the $0-20$ and $20-40 \mathrm{~cm}$ layers and of 0.64 between the $0-20$ and $120-140 \mathrm{~cm}$ layers on a sampling date during a recharge period. They further investigated the scale-specific similarity of the spatial pattern of soil-water storage between surface soil and subsurface depths using wavelet coherency. The correlation coefficient decreased with increasing depth, perhaps because the influence of the

Table 2

Matrix of Pearson correlation coefficients among mean SWCs at each soil depth $(\mathrm{cm})$.

\begin{tabular}{|c|c|c|c|c|c|c|c|c|c|c|c|c|c|c|c|}
\hline & 20 & 40 & 60 & 80 & 100 & 120 & 140 & 160 & 180 & 200 & 220 & 240 & 260 & 280 & 300 \\
\hline 10 & $0.91^{* *}$ & $0.79^{* * *}$ & $0.72^{* *}$ & $0.66^{* *}$ & $0.63^{* *}$ & $0.60^{* *}$ & $0.50^{* *}$ & $0.51^{* *}$ & $0.46^{* *}$ & $0.38^{* *}$ & $0.32^{* *}$ & $0.32^{* *}$ & $0.32^{* *}$ & $0.29^{* *}$ & $0.29^{* *}$ \\
\hline 20 & & $0.93^{* *}$ & $0.83^{* *}$ & $0.78^{* *}$ & $0.76^{* *}$ & $0.73^{* *}$ & $0.61^{* *}$ & $0.60^{* *}$ & $0.55^{* *}$ & $0.45^{* *}$ & $0.39^{* *}$ & $0.38^{* *}$ & $0.37^{* *}$ & $0.35^{* *}$ & $0.35^{* *}$ \\
\hline 40 & & & $0.92^{* *}$ & $0.88^{* *}$ & $0.85^{* *}$ & $0.81^{* *}$ & $0.68^{* *}$ & $0.65^{* *}$ & $0.59^{* *}$ & $0.49^{* *}$ & $0.43^{* *}$ & $0.42^{* *}$ & $0.41^{* *}$ & $0.38^{* *}$ & $0.38^{* *}$ \\
\hline 60 & & & & $0.97^{* *}$ & $0.91^{* *}$ & $0.85^{* *}$ & $0.74^{* *}$ & $0.70^{* *}$ & $0.64^{* *}$ & $0.52^{* *}$ & $0.45^{* *}$ & $0.43^{* *}$ & $0.42^{* *}$ & $0.39^{* *}$ & $0.39^{* *}$ \\
\hline 80 & & & & & $0.96^{* *}$ & $0.91^{* *}$ & $0.79^{* *}$ & $0.74^{* *}$ & $0.68^{* *}$ & $0.58^{* *}$ & $0.51^{* *}$ & $0.48^{* *}$ & $0.47^{* *}$ & $0.44^{* *}$ & $0.44^{* *}$ \\
\hline 100 & & & & & & $0.97^{* *}$ & $0.84^{* *}$ & $0.78^{* *}$ & $0.73^{* *}$ & $0.62^{* *}$ & $0.55^{* *}$ & $0.53^{* *}$ & $0.51^{* *}$ & $0.48^{* *}$ & $0.47^{* *}$ \\
\hline 120 & & & & & & & $0.90^{* *}$ & $0.85^{* *}$ & $0.80^{* *}$ & $0.69^{* *}$ & $0.62^{* *}$ & $0.60^{* *}$ & $0.58^{* *}$ & $0.55^{* *}$ & $0.55^{* *}$ \\
\hline 140 & & & & & & & & $0.97^{* *}$ & $0.92^{* *}$ & $0.82^{* *}$ & $0.75^{* *}$ & $0.73^{* *}$ & $0.72^{\text {** }}$ & $0.71^{\text {** }}$ & $0.70^{* *}$ \\
\hline 160 & & & & & & & & & $0.97^{* *}$ & $0.87^{* *}$ & $0.81^{* *}$ & $0.79^{* *}$ & $0.78^{* *}$ & $0.76^{* *}$ & $0.76^{* *}$ \\
\hline 180 & & & & & & & & & & $0.94^{* *}$ & $0.88^{* *}$ & $0.85^{* *}$ & $0.83^{* *}$ & $0.81^{* *}$ & $0.81^{* *}$ \\
\hline 200 & & & & & & & & & & & $0.96^{* *}$ & $0.92^{* *}$ & $0.89^{* *}$ & $0.86^{* *}$ & $0.85^{* *}$ \\
\hline 220 & & & & & & & & & & & & $0.97^{* *}$ & $0.92^{* *}$ & $0.88^{* *}$ & $0.88^{* *}$ \\
\hline 240 & & & & & & & & & & & & & $0.97^{* *}$ & $0.94^{* *}$ & $0.93^{* *}$ \\
\hline 260 & & & & & & & & & & & & & & $0.98^{* *}$ & $0.97^{* *}$ \\
\hline 280 & & & & & & & & & & & & & & & 1.00 \\
\hline
\end{tabular}

** Correlation is significant at the 0.01 level (2-tailed). 


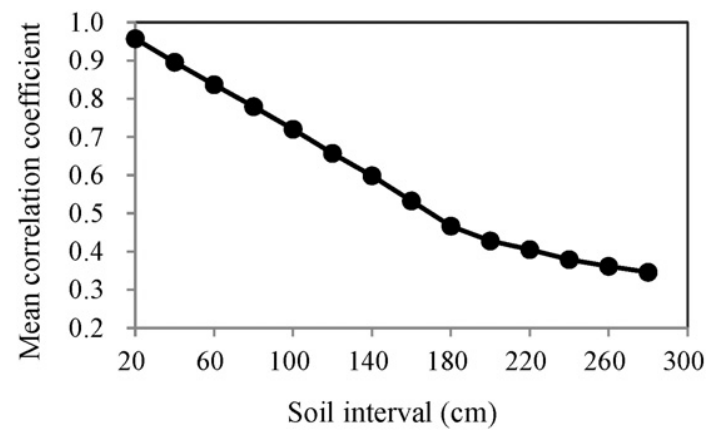

Fig. 5. Mean Pearson correlation coefficients corresponding to different soil intervals along the transect.

soil-water processes controlling the spatial patterns of SWC gradually decreased with greater distances between depths. Jia et al. (2013b), however, found an inconsistent trend of SWC correlation coefficients in four plots containing different types of vegetation. For example, the correlation coefficients in a plot with Korshinsk Peashrubs between the SWC at $10 \mathrm{~cm}$ and at $20,30,50$, and $100 \mathrm{~cm}$ were $0.388,0.348$, 0.869 , and 0.492 , respectively. Vegetational cover may thus significantly affect the similarity in the spatial pattern of soil moisture among surface and subsurface depths.

\subsection{Distribution of temporal stability of SWC within the soil profile}

\subsubsection{Temporal stability of SWC in the soil profile}

Spearman's rank correlation analysis was used to investigate the overall temporal persistence of spatial patterns of SWC between different sampling dates. $r_{s}$ was statistically significant $(P<0.01)$ between any two sampling dates for each soil depth (data not shown), indicating a strong temporal persistence of SWC, in accordance with the findings of previous reports (Brocca et al., 2009; Gao and Shao, 2012a; Zhang and Shao, 2013; Wang et al., 2013; Hu et al., 2014). Fig. 6a shows the mean $r_{s}$ for each depth within the profile. The mean $r_{s}$ at $10 \mathrm{~cm}$ was 0.879 and increased rapidly to 0.942 at $20 \mathrm{~cm}$. The mean $r_{s}$ fluctuated within a small range from 20 to $180 \mathrm{~cm}$. For example, the mean $r_{s}$ were $0.937,0.943$, and 0.942 at 60,120 , and $180 \mathrm{~cm}$, respectively. The mean $r_{s}$ did not differ significantly $(P<0.05)$ among the 60,120 , and $180 \mathrm{~cm}$ depths (Fig. 6a, Table 3). The lack of significant differences in mean $r_{s}$ between the depths may be ascribed to the similar soil water infiltration and evapotranspiration processes at 20-180 cm depths within a specific soil profile of this study. Below $180 \mathrm{~cm}$, the mean $r_{s}$ gradually increased to 0.979 at $300 \mathrm{~cm}$. The trend of $r_{s}$ along the profile was in disagreement with that of other studies (Cassel et al., 2000; Lin, 2006; Guber et al., 2008; Gao and Shao, 2012a; Penna et al., 2013),
Table 3

Statistical summary of the Spearman's rank correlation coefficients for various soil depths.

\begin{tabular}{lllllll}
\hline Parameter & $10 \mathrm{~cm}$ & $60 \mathrm{~cm}$ & $120 \mathrm{~cm}$ & $180 \mathrm{~cm}$ & $240 \mathrm{~cm}$ & $300 \mathrm{~cm}$ \\
\hline Mean & $0.879 \mathrm{a}^{\S}$ & $0.937 \mathrm{~b}$ & $0.943 \mathrm{~b}$ & $0.942 \mathrm{~b}$ & $0.967 \mathrm{c}$ & $0.979 \mathrm{~d}$ \\
Max & 0.986 & 0.990 & 0.990 & 0.992 & 0.994 & 0.997 \\
Min & 0.725 & 0.857 & 0.842 & 0.833 & 0.893 & 0.930 \\
SD & 0.060 & 0.029 & 0.032 & 0.042 & 0.025 & 0.016 \\
CV,\% & 6.787 & 3.099 & 3.355 & 4.413 & 2.613 & 1.606 \\
\hline
\end{tabular}

$\S$ Different lowercase letters within a row indicate significant differences determined by Duncan's Multiple Range Test $(P<0.05)$.

where the mean $r_{s}$ increased with depth. The different depths of sampling in these studies may not have been able to detect precise changes in mean $r_{s}$ along the soil profile. Given that the thickness of the soil layers can affect the trend of $r_{s}$, the division of soil profile should be considered.

\subsubsection{Temporal stability of SWC at individual locations}

Fig. 7 shows the rank-ordered MRD in SWC and the associated SDRD for each sampling location for six selected soil depths. The range between the minimum and maximum MRDs was $242.2 \%$ at $10 \mathrm{~cm}$, decreased to $165.4 \%$ at $60 \mathrm{~cm}$, and then gradually increased to $263.7 \%$ at $300 \mathrm{~cm}$ (Table 4). The distribution of the range of MRD along the soil profile corresponded with the distribution of the $\mathrm{CV}_{\mathrm{S}}$ (Fig. $4 \mathrm{~b}$, Table 1). The cause of the spatial variability in shallow soil, however, may differ from that in deeper soil. The relatively greater range of MRD at $10 \mathrm{~cm}$ may be attributed to the stronger influence on the spatial variability of SWC of processes such as rainfall, evapotranspiration, and runoff. The increasing ranges of MRD across the 60-300 cm depths, however, may be mostly due to the wider range of soil texture with increasing depth in this area (Hu et al., 2010b). In addition, the absolute values of the minimum MRDs were lower than those of the maximum MRDs at each selected depth (Fig. 7, Table 4), in agreement with previous observations (Cosh et al., 2008; Jia et al., 2013a).

The mean SDRD and MABE both decreased with increasing depth from 10 to $300 \mathrm{~cm}$ (Fig. 6b, Table 4). The mean SDRDs were 16.2, 9.9, 9.1, 8.8, 6.9, and $6.1 \%$ and the mean MABEs were 15.0, 8.9, 8.4, 7.9, 6.0, and $5.4 \%$ at $10,60,120,180,240$, and $300 \mathrm{~cm}$, respectively (Table 4). Similar results have also been reported for a desert area (Wang et al., 2013), a forest ecosystem (Lin, 2006), and a semi-arid hillslope (Gao and Shao, 2012a, b). SDRD and MABE decreased rapidly between 10 and $40 \mathrm{~cm}$ (Fig. $6 \mathrm{~b}$ ) and decreased gradually below $40 \mathrm{~cm}$. The analysis of Spearman's rank correlations is a different method from the analysis of SDRD or MABE, but these methods have identified similar trends of temporal stability. Increasing temporal stability with depth is mainly due to a decrease in the dependence of SWC on climatic, biological, and hydrological factors with increasing depth (Hupet and Vanclooster, 2002; Starks et al., 2006; Gao and Shao, 2012a) such as rainfall, root
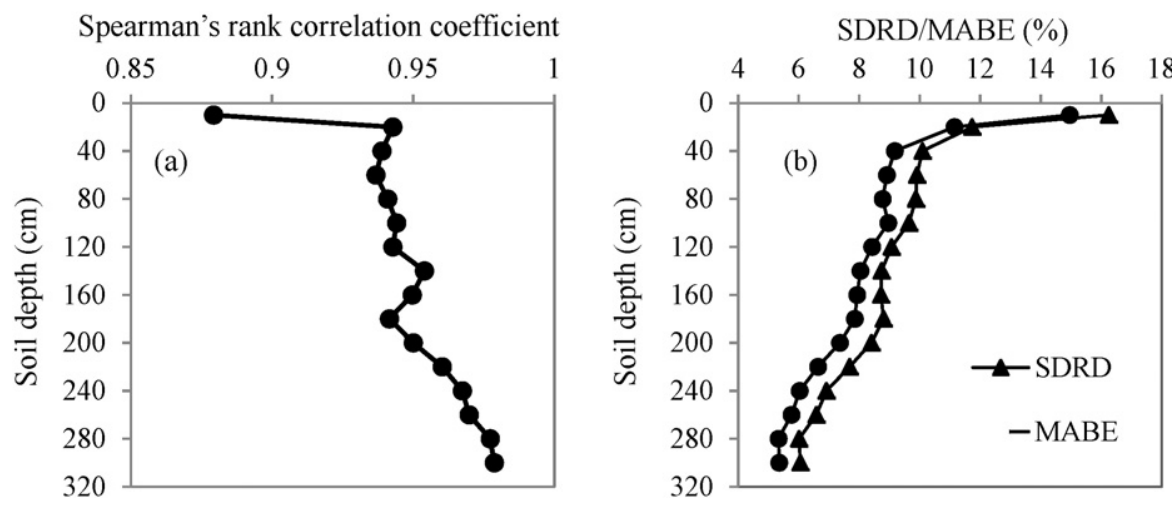

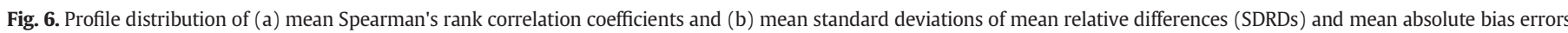
(MABEs). 


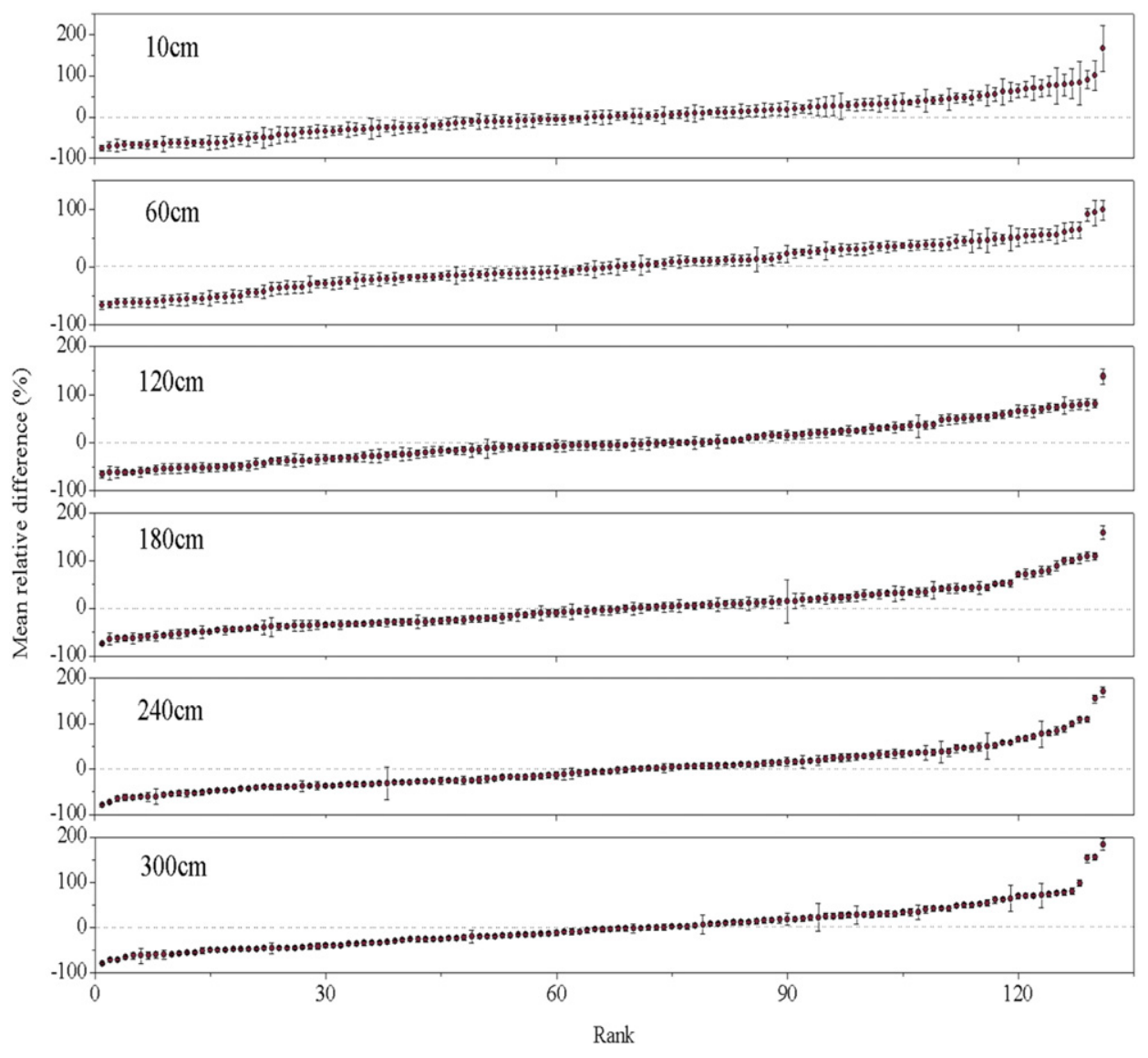

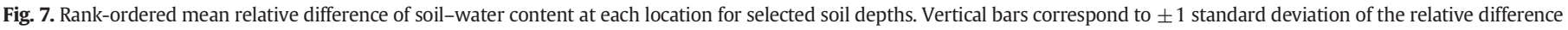
over time.

activity, and runoff. Moreover, soil structure and the ability of soil to retain moisture are more variable in shallow soil (Korsunskaya et al., 1995).

The number of locations with an MRD between -5 and $5 \%$ fluctuated with increasing depths: $12,11,17,12,9$, and 13 for $10,60,120,180$, 240 , and $300 \mathrm{~cm}$ depths, respectively (Fig. 8a), indicating the lack of dependence on depth. Locations with an SDRD and/or MABE under 5\% are considered to be temporally stable (Starks et al., 2006; Hu et al., 2010a). The number of temporally stable locations increased with depth (Fig. 8a). For example, the number of the 135 locations with an SDRD or MABE under $5 \%$ was 0 or 3 , respectively, at $10 \mathrm{~cm}$ but rapidly increased to 76 or 95 , respectively, at $300 \mathrm{~cm}$, i.e. more than half of the sampling locations.

Table 4

Statistical summary of the mean relative differences (MRDs), standard deviations of MRD (SDRDs), and mean absolute bias errors (MABEs) in soil-water content for various soil depths.

\begin{tabular}{llcccccc}
\hline Parameter & & $10 \mathrm{~cm}$ & $60 \mathrm{~cm}$ & $120 \mathrm{~cm}$ & $180 \mathrm{~cm}$ & $240 \mathrm{~cm}$ & $300 \mathrm{~cm}$ \\
\hline MRD (\%) & Max & 166.2 & 98.1 & 138.0 & 158.7 & 169.8 & 183.5 \\
& Min & -76.0 & -67.3 & -65.3 & -74.6 & -79.4 & -80.3 \\
& Range & 242.2 & 165.4 & 203.4 & 233.2 & 249.2 & 263.7 \\
SDRD (\%) & Mean & $16.2 \mathrm{a}$ & $9.9 \mathrm{~b}$ & $9.1 \mathrm{~b}$ & $8.8 \mathrm{~b}$ & $6.9 \mathrm{c}$ & $6.1 \mathrm{c}$ \\
& Max & 56.1 & 22.4 & 24.1 & 45.1 & 35.5 & 31.4 \\
& Min & 5.8 & 4.2 & 3.7 & 2.4 & 2.0 & 2.2 \\
& Range & 50.3 & 18.1 & 20.4 & 42.7 & 33.5 & 29.2 \\
MABE (\%) & Mean & $15.0 \mathrm{a}$ & $8.9 \mathrm{~b}$ & $8.4 \mathrm{~b}$ & $7.9 \mathrm{~b}$ & $6.0 \mathrm{c}$ & $5.4 \mathrm{c}$ \\
& Max & 40.2 & 21.8 & 25.8 & 33.1 & 35.7 & 30.8 \\
& Min & 3.3 & 2.4 & 3.0 & 2.1 & 1.7 & 1.6 \\
& Range & 36.9 & 19.4 & 22.8 & 31.0 & 34.0 & 29.2 \\
\hline
\end{tabular}

$\S$ Different lowercase letters within a row indicate significant differences determined by Duncan's Multiple Range Test $(P<0.05)$.
A location with an allowable bias of 5\% for both MRD and SDRD simultaneously is defined as a representative location (Gao and Shao, 2012a). Neither the number of locations with an MRD between -5 and $5 \%$ nor the number of representative locations was depthdependent (Fig. 8b). The number of representative locations were 0,0 , $2,0,0$, and 5 at $10,60,120,180,240$, and $300 \mathrm{~cm}$, respectively, inconsistent with the findings by Gao and Shao (2012a) and Jia et al. (2013a). Gao and Shao (2012a), for example, identified 3, 5, and 8 representative locations for the depths of $0-100,100-200$, and $200-300 \mathrm{~cm}$, respectively. The inconsistent results may be attributed to the different depths of sampling. The SWC of thinner depth was more susceptible to climate, landform, soil properties, and/or plants, resulting in reduction of representative locations for various soil layers. In addition, our representative locations were mainly for deeper soil (200-300 cm) (Fig. 8b).

The most important application of temporal stability is to estimate the mean SWC of an area of interest using the SWC of a representative location directly. Representative locations, however, could not be directly identified for most depths in the present study (Fig. 8b). Mean SWC can be evaluated indirectly by Eq. (6) if a constant offset is introduced (Grayson and Western, 1998). The results of a linear-fitting analysis between the estimated and the measured soil mean SWCs for each depth are presented in Table 5. The direct method was commonly used for 200-300 cm depths, and the indirect method was used for 10$180 \mathrm{~cm}$ depths. Both methods estimated the mean SWCs well based on the low MAREs and RMSEs. For example, the MAREs and RMSEs ranged from 0.02 to $0.08 \%$ and from 0.41 to $1.39 \%$, respectively (Table 5). Gao et al. (2011) found that the direct and indirect methods had similar and good predictive accuracies for estimating field-mean moistures of jujube orchards. Wang et al. (2013) observed a stronger linear relationship between field-mean and estimated mean SWC using the indirect method, with values within acceptable error limits. 

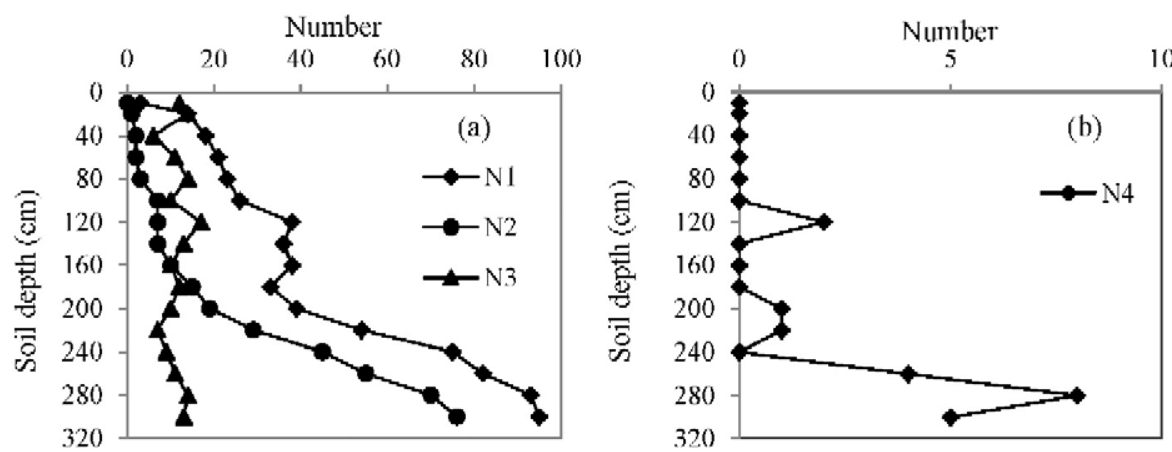

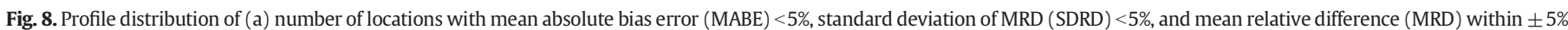

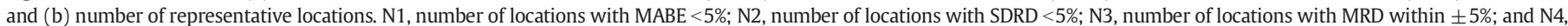
number of locations with MRD within $\pm 5 \%$ and SDRD $<5 \%$.

The MARE and RMSE were relatively higher at $120-180 \mathrm{~cm}$ than in shallower and/or deeper soil (Table 5). There were two reasons for this result. First of all, the SWC of shallow soil was mainly controlled by external condition, while the SWC of deep soil was less affected. However, the intermediate depths $(120-180 \mathrm{~cm})$ could capture the soil water exchange between the shallow and deep soils, resulting in relatively higher values of MARE and RMSE. Moreover, the uneven distribution of roots for 120-180 cm depth, especially for species with higher evapotranspiration (e.g. alfalfa), could also complicate the water dynamics (Zhao et al., 2010).

Linear fitting analysis was also performed between the measured mean SWC and the estimated mean SWC calculated with Eq. (6) along the entire soil profile (Fig. 9) to further evaluate the indirect method. The method estimated the mean SWCs accurately $\left(R^{2}=0.9993\right.$, $P<0.001)$ within the soil profile. Temporal stability tends to vary with depth (Vanderlinden et al., 2012), but finding a single location representing the mean SWC for several depths can both reduce costs and maintain a high accuracy of prediction. In the present study, locations 10 and 127 were able to represent two depths, and location 35 could represent three depths (Table 5).

\subsection{Characteristics of the temporal stability of SWC under different soil-moisture conditions}

The temporal stability of SWC is associated with soil-moisture conditions (Hu et al., 2010b; Gao and Shao, 2012a; Zhang and Shao, 2013). In

\section{Table 5}

Linear fitting between measured soil-water content (SWC) ( $x$ ) and the estimated SWC $(y)$ using direct or indirect methods for each depth along the transect.

\begin{tabular}{lcllll}
\hline Depth $(\mathrm{cm})$ & Location & Fitting equation & MARE $(\%)$ & RMSE $(\%)$ & Method \\
\hline 10 & 89 & $y=0.957 x+0.356$ & 0.03 & 0.42 & Indirect \\
20 & 91 & $y=0.993 x+0.102$ & 0.03 & 0.41 & Indirect \\
40 & 10 & $y=0.990 x+0.130$ & 0.04 & 0.86 & Indirect \\
60 & 131 & $y=0.842 x+2.388$ & 0.02 & 0.48 & Indirect \\
80 & 12 & $y=1.053 x-0.768$ & 0.04 & 0.80 & Indirect \\
100 & 10 & $y=1.001 x-0.024$ & 0.03 & 0.61 & Indirect \\
120 & 114 & $y=0.766 x+3.190$ & 0.07 & 1.14 & Direct \\
140 & 69 & $y=0.242 x+10.341$ & 0.07 & 1.39 & Indirect \\
160 & 35 & $y=1.527 x-7.116$ & 0.08 & 1.36 & Indirect \\
180 & 35 & $y=0.851 x+2.024$ & 0.07 & 1.20 & Indirect \\
200 & 84 & $y=0.642 x+4.784$ & 0.04 & 0.71 & Direct \\
220 & 25 & $y=1.039 x-0.667$ & 0.04 & 0.66 & Direct \\
240 & 35 & $y=2.022 x-14.365$ & 0.05 & 1.03 & Indirect \\
260 & 5 & $y=0.698 x+4.407$ & 0.03 & 0.57 & Direct \\
280 & 127 & $y=0.701 x+4.275$ & 0.03 & 0.48 & Direct \\
300 & 127 & $y=0.590 x+6.150$ & 0.03 & 0.54 & Direct \\
\hline
\end{tabular}

Direct method indicates that the representative location was identified by the location with mean relative difference (MRD) within $\pm 5 \%$ and standard deviation of mean relative difference $(S D R D)<5 \%$; indirect method indicates that the representative location was identified by the most temporally stable location; MARE was mean absolute relative error; RMSE was root mean square error. the present study, four types of representative locations, the driest, wettest, mean moisture and most temporally stable, were thus identified for each soil depth along the transect. The location numbers, MRDs, and SDRDs for the four soil-moisture conditions at each depth are presented in Table 6.

No single location was representative across the soil profile under all four moisture conditions, but the locations for the extreme conditions (the driest and wettest conditions) of moisture were consistently representative for several depths. For example, location 31 represented depths of 220,240,260,280, and $300 \mathrm{~cm}$ under the driest conditions, and location 29 represented depths of $160,180,200,220,240$, and $260 \mathrm{~cm}$ under the wettest conditions. The locations representing several depths for the most temporally stable moisture conditions were mainly for deeper soil. No location under mean moisture conditions, however, could represent two adjacent depths (Table 6), indicating that extreme conditions may be persistent along soil profiles. This result was in agreement with the findings by Jia et al. (2013b).

The wettest locations had relatively higher SDRDs, mean-moisture locations had moderate SDRDs, and the driest locations had relatively lower SDRDs for each depth. The driest locations were thus more likely to be the most temporally stable. For example, locations 35 and 31 were identified as both the driest and the most temporally stable locations for the $160-200 \mathrm{~cm}$ and $260-300 \mathrm{~cm}$ depths, respectively (Table 6). These results were consistent with those of other studies (MartínezFernández and Ceballos, 2003; Jacobs et al., 2004; Cosh et al., 2008; Hu et al., 2010b; Gao and Shao, 2012a; Jia et al., 2013b). Hu et al. (2010b) and Gao and Shao (2012a) found a significant positive correlation $(P<0.01)$ between SWC and the associated SDRD. In the present study, the soils of locations 35 and 31 were characterised as sandy soil. Drier sandy soils may have lower SDRDs due to their inability to retain water (Martínez-Fernández and Ceballos, 2003). Schneider et al.

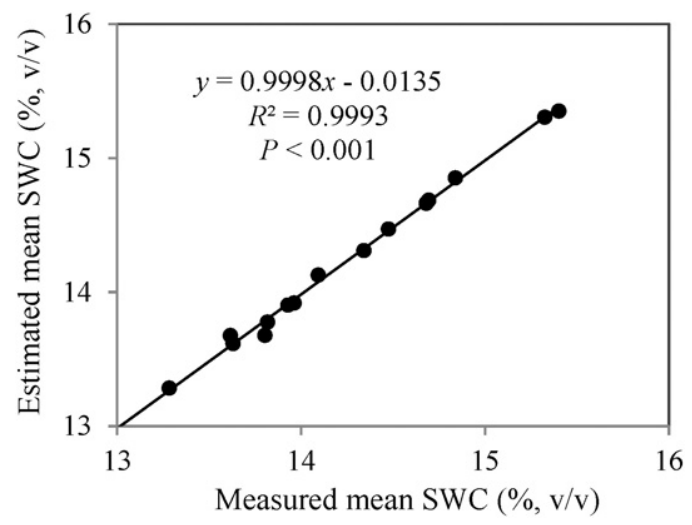

Fig. 9. Linear fitting between measured mean soil-water content (SWC) $(x)$ and estimated mean SWC $(y)$ calculated with Eq. (6) for each soil depth of the soil profile. 
Table 6

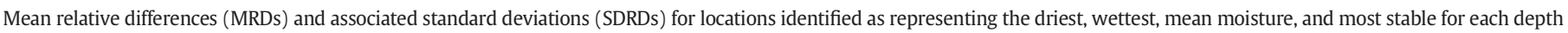
along the transect.

\begin{tabular}{|c|c|c|c|c|c|c|c|c|c|c|c|c|}
\hline \multirow{2}{*}{$\begin{array}{l}\text { Depth } \\
(\mathrm{cm})\end{array}$} & \multicolumn{3}{|c|}{ Driest locations } & \multicolumn{3}{|c|}{ Mean moisture locations } & \multicolumn{3}{|c|}{ Wettest locations } & \multicolumn{3}{|c|}{ Most stable locations } \\
\hline & No. & $\operatorname{MRD}(\%)$ & SDRD (\%) & No. & $\operatorname{MRD}(\%)$ & SDRD (\%) & No. & MRD (\%) & SDRD (\%) & No. & SDRD (\%) & MRD (\%) \\
\hline 10 & 58 & -75.97 & 6.97 & 115 & 0.01 & 16.85 & 29 & 166.20 & 56.07 & 89 & 5.80 & 35.32 \\
\hline 20 & 58 & -69.65 & 7.07 & 1 & -0.32 & 7.02 & 29 & 106.56 & 34.28 & 91 & 4.59 & 25.75 \\
\hline 40 & 58 & -62.66 & 8.03 & 115 & 0.80 & 15.54 & 118 & 90.00 & 13.48 & 10 & 4.49 & -12.98 \\
\hline 60 & 59 & -67.27 & 7.29 & 123 & 0.27 & 14.16 & 89 & 98.11 & 17.15 & 131 & 4.25 & 36.63 \\
\hline 80 & 87 & -75.01 & 2.98 & 104 & -0.06 & 8.78 & 89 & 121.02 & 19.52 & 12 & 2.78 & -48.39 \\
\hline 100 & 37 & -67.17 & 6.38 & 121 & 0.02 & 7.65 & 89 & 126.48 & 19.09 & 10 & 3.61 & -16.06 \\
\hline 120 & 37 & -65.33 & 6.74 & 85 & 0.09 & 5.41 & 89 & 138.04 & 16.16 & 31 & 3.69 & -61.11 \\
\hline 140 & 35 & -67.79 & 4.47 & 107 & -0.81 & 11.09 & 89 & 128.52 & 15.96 & 69 & 3.65 & -59.84 \\
\hline 160 & 35 & -72.72 & 2.68 & 105 & 0.06 & 7.29 & 29 & 157.29 & 14.21 & 35 & 2.68 & -72.72 \\
\hline 180 & 35 & -74.56 & 2.37 & 53 & -0.20 & 12.82 & 29 & 158.69 & 14.26 & 35 & 2.37 & -74.56 \\
\hline 200 & 35 & -77.87 & 2.34 & 102 & 0.56 & 7.70 & 29 & 181.66 & 17.67 & 35 & 2.34 & -77.87 \\
\hline 220 & 31 & -77.30 & 7.77 & 103 & -0.35 & 6.36 & 29 & 174.16 & 13.85 & 35 & 2.56 & -75.85 \\
\hline 240 & 31 & -79.41 & 2.65 & 88 & 0.15 & 5.09 & 29 & 169.75 & 10.84 & 35 & 1.99 & -72.92 \\
\hline 260 & 31 & -78.66 & 2.42 & 120 & 0.24 & 4.45 & 29 & 163.36 & 9.41 & 31 & 2.42 & -78.66 \\
\hline 280 & 31 & -79.42 & 1.81 & 5 & -0.02 & 4.32 & 74 & 162.19 & 10.63 & 31 & 1.81 & -79.42 \\
\hline 300 & 31 & -80.26 & 2.17 & 0 & -0.41 & 5.90 & 74 & 183.45 & 13.07 & 31 & 2.17 & -80.26 \\
\hline
\end{tabular}

(2008), however, did not find a significant dependence of temporal stability on soil-water status. Additionally, the SDRDs of our locations with the above four moisture conditions tended to decrease with increasing depth, indicating that the temporal stability at those representative locations increased as external disturbances decreased along the soil profile.

\section{Conclusions}

This study analysed the changing characteristics of SWC and its temporal stability in soil profile. Based on the SWC datasets of 135 locations on 18 observing dates, the following conclusions can be summarized:

The $\mathrm{SD}_{\mathrm{T}}$ and $\mathrm{CV}_{\mathrm{T}}$ of SWC decreased with soil depth. The $\mathrm{SD}_{\mathrm{S}}$ of $\mathrm{SWC}$ decreased with depth, but the $\mathrm{CV}_{\mathrm{S}}$ first decreased and then increased below $60 \mathrm{~cm}$. Significant depth persistence of the spatial pattern of SWC was observed among the various depths, and the persistence decreased with increasing soil intervals.

The temporal stability of SWC was relatively higher in deeper than in shallower soil based on Spearman's rank correlation coefficients, SDRDs, and MABEs. The changes in these indices, however, differed to some extent along the soil profile. The number of locations with an SDRD and/or MABE $<5 \%$ was significantly dependent on depth, but the number of locations with an MRD within $\pm 5 \%$ and/or representative locations was not depth-dependent.

The mean SWC for each soil depth can be accurately estimated by MARE and RMSE directly using the SWCs of representative locations or indirectly using the most temporally stable locations, and the accuracy of prediction was not depth-dependent. A single location can remain representative for more depths under extreme moisture conditions than under mean moisture conditions. Drier locations were more likely to be the most temporally stable, especially for deep soils.

The distribution of Spearman's rank correlation coefficients and the number of representative locations along the soil profile differed from those of previous studies. These differences may indicate that information can be neglected if soil profiles are sectioned coarsely. This study contributes to our further understanding of the SWC patterns in semiarid regions and has important implications for hydrological modelling and the management of soil water.

\section{Acknowledgement}

This study was financially supported by the National Natural Science Foundation of China (Nos. 51179180 and 41390463).

\section{References}

Biswas, A., Si, B.C., 2011a. Depth persistence of the spatial pattern of soil water storage in a hummocky landscape. Soil Sci. Soc. Am. J. 75, 1099-1109.

Biswas, A., Si, B.C., 2011b. Identifying scale specific controls of soil water storage in a hummocky landscape using wavelet coherency. Geoderma 165, 50-59.

Brocca, L., Melone, F., Moramarco, T., Morbidelli, R., 2009. Soil moisture temporal stability over experimental areas in Central Italy. Geoderma 148, 364-374.

Cassel, D.K., Wendroth, O., Nielsen, D.R., 2000. Assessing spatial variability in an agricultural experiment station field: opportunities arising from spatial dependence. Agron. J. 92, 706-714.

Choi, M., Jacobs, J.M., 2007. Soil moisture variability of root zone profiles within SMEX02 remote sensing footprints. Adv. Water Resour. 30, 883-896.

Choi, M., Jacobs, J.M., 2011. Spatial soil moisture scaling structure during soil moisture experiment 2005. Hydrol. Process. 25, 926-932.

Cosh, M.H., Jackson, T.J., Moran, S., Bindlish, R., 2008. Temporal persistence and stability of surface soil moisture in a semi-arid watershed. Remote Sens. Environ. 112, 304-313.

da Silva, A.P., Nadler, A., Kay, B.D., 2001. Factors contributing to temporal stability in spatial patterns of water content in the tillage zone. Soil Tillage Res. 58, 207-218.

De Lannoy, G.J.M., Verhoest, N.E.C., Houser, P.R., Gish, T.J., Meirvenne, M.V., 2006. Spatial and temporal characteristics of soil moisture in an intensively monitored agricultural field $\left(\mathrm{OPE}^{3}\right)$. J. Hydrol. 331, 719-730.

de Rosnay, P., Gruhier, C., Timouk, F., Baup, F., Mougin, E., Hiernaux, P., Kergoat, L., LeDantec, V., 2009. Multi-scale soil moisture measurements at the Gourma mesoscale site in Mali. J. Hydrol. 375, 241-252.

Famiglietti, J.S., Ryu, D., Berg, A.A., Rodell, M., Jackson, T.J., 2008. Field observations of soil moisture variability across scales. Water Resour. Res. 44, W01423.

Fernandez, J.M., Ceballos, A., 2005. Mean soil moisture estimation using temporal stability analysis. J. Hydrol. 312, 28-38.

Gao, L., Shao, M.A., 2012a. Temporal stability of soil water storage in diverse soil layers. Catena 95, 24-32.

Gao, L., Shao, M.A., 2012b. Temporal stability of shallow soil water content for three adjacent transects on a hillslope. Agric. Water Manag. 110, 41-54.

Gao, X.D., Wu, P.T., Zhao, X.N., Shi, Y.G., Wang, J.W., 2011. Estimating spatial mean soil water contents of sloping jujube orchards using temporal stability. Agric. Water Manag. 102, 66-73.

Garcia-Estringana, P., Latron, J., Llorens, P., Gallart, F., 2012. Spatial and temporal dynamics of soil moisture in a Mediterranean mountain area (Vallcebre, NE Spain). Ecohydrology 6, 741-753.

Gómez-Plaza, A., Alvarez-Rogel, J., Albaladejo, J., Castillo, V.M., 2000. Spatial patterns and temporal stability of soil moisture across a range of scales in a semi-arid environment. Hydrol. Process. 14, 1261-1277.

Grayson, R.B., Western, A.W., 1998. Towards areal estimation of soil water content from point measurements: time and space stability of mean response. J. Hydrol. 207, 68-82.

Grayson, R.B., Western, A.W., Chiew, F.H.S., Blöschl, G., 1997. Preferred states in spatial soil moisture patterns: local and nonlocal controls. Water Resour. Res. 33, 2897-2908.

Guber, A.K., Gish, T.J., Pachepsky, Y.A., van Genuchten, M.T., Daughtry, C.S.T., Nicholson, T.J., Cady, R.E., 2008. Temporal stability in soil water content patterns across agricultural fields. Catena 73, 125-133.

Heathman, G.C., Larose, M., Cosh, M.H., Bindlish, R., 2009. Surface and profile soil water spatio-temporal analysis during an excessive rainfall period in the Southern Great Plains, USA. Catena 78, 159-169.

Heathman, G.C., Cosh, M.H., Merwade, V., Han, E., 2012. Multi-scale temporal stability analysis of surface and subsurface soil moisture within the Upper Cedar Creek Watershed, Indiana. Catena 95, 91-103.

Hu, W., Shao, M.A., Wang, Q.J., Reichardt, K., 2009. Time stability of soil water storage measured by neutron probe and the effects of calibration procedures in a small watershed. Catena 79, 72-82. 
Hu, W., Shao, M.A., Reichardt, K., 2010a. Using a new criterion to identify sites for mean soil water storage evaluation. Soil Sci. Soc. Am. J. 74, 762-773.

Hu, W., Shao, M.A., Wang, Q.J., Reichardt, K., Tan, J., 2010b. Watershed scale temporal stability of soil water content. Geoderma 158, 181-198.

Hu, W., Biswas, A., Si, B.C., 2014. Application of multivariate empirical mode decomposition for revealing scale- and season-specific time stability of soil water storage. Catena 113, 377-385.

Hupet, F., Vanclooster, M., 2002. Intraseasonal dynamics of soil moisture variability within a small agricultural maize cropped field. J. Hydrol. 261, 86-101.

Jacobs, J.M., Mohanty, B.P., Hsu, E.C., Miller, D., 2004. SME02: field scale variability, time stability and similarity of soil moisture. Remote Sens. Environ. 92, 436-446.

Jia, Y.H., Shao, M.A., 2013. Temporal stability of soil water storage under four types of revegetation on the northern Loess Plateau of China. Agric. Water Manag. 117, 33-42.

Jia, X.X., Shao, M.A., Wei, X.R., Wang, Y.Q., 2013a. Hillslope scale temporal stability of soil water storage in diverse soil layers. J. Hydrol. 498, 254-264.

Jia, Y.H., Shao, M.A., Jia, X.X., 2013b. Spatial pattern of soil moisture and its temporal stability within profiles on a loessial slope in northwestern China. J. Hydrol. 495, 150-161.

Korsunskaya, L.P., Gummatov, N.G., Pachepsky, Ya.A., 1995. Seasonal changes in root biomass carbohydrate content, and structural characteristics of Gray Forest soil. Eurasian Soil Sci. 27, 45-52.

Lawrence, J.E., Hornberger, G.M., 2007. Soil moisture variability across climate zones. Geophys. Res. Lett. 34, L20402.

Li, X.Z., Shao, M.A., Jia, X.X., Wei, X.R., 2015. Landscape-scale temporal stability of soil water storage within profiles on the semiarid Loess Plateau of China. J. Soils Sediments 15, 949-961.

Lin, H., 2006. Temporal stability of soil moisture spatial pattern and subsurface preferential flow pathways in the Shale Hills catchment. Vadose Zone J. 5, 317-340.

Liu, B.X., Shao, M.A., 2014. Estimation of soil water storage using temporal stability in four land uses over 10 years on the Loess Plateau. China J. Hydrol. 517, 974-984.

Manfreda, S., Rodriguez-Iturbe, I., 2006. On the spatial and temporal sampling of soil moisture fields. Water Resour. Res. 42, W05409.

Martínez-Fernández, J., Ceballos, A., 2003. Temporal stability of soil moisture in a largefield experiment in Spain. Soil Sci. Soc. Am. J. 67, 1647-1656.

Martínez-Fernández, J., Ceballos, A., 2005. Mean soil water estimation using temporal stability analysis. J. Hydrol. 312, 28-38.
Mohanty, B.P., Skaggs, T.H., 2001. Spatio-temporal evolution and time-stable characteristics of soil moisture within remote sensing footprints with varying soil, slope, and vegetation. Adv. Water Resour. 24, 1051-1067.

Nielson, D., Bouma, J., 1985. Soil spatial variability. Pudoc, Wageningen, Netherlands.

Penna, D., Brocca, L., Borga, M., Dalla Fontana, G., 2013. Soil moisture temporal stability at different depths on two alpine hillslopes during wet and dry periods. J. Hydrol. 477, 55-71.

Peterson, E.W., Wicks, C.M., 2006. Assessing the importance of conduit geometry and physical parameters in karst systems using the storm water management mode (SWMM). J. Hydrol. 329, 294-305.

Schneider, K., Huisman, J.A., Breuer, L., Zhao, Y., Frede, H.G., 2008. Temporal stability of soil moisture in various semi-arid steppe ecosystems and its application in remote sensing. J. Hydrol. 359, 16-29.

Starks, P.J., Heathman, G.C., Jackson, T.J., Cosh, M.H., 2006. Temporal stability of soil moisture profile. J. Hydrol. 324, 400-411.

Tallon, L.K., Si, B.C., 2004. Representative soil water benchmarking for environmental monitoring. J. Environ. Inform. 4, 28-36.

Tromp-van Meerveld, H.J., McDonnell, J.J., 2006. On the interrelations between topography, soil depth, soil moisture, transpiration rates and species distribution at the hillslope scale. Adv. Water Resour. 29, 293-310.

Vachaud, G., Passerat de Silans, A., Balabanis, P., Vauclin, M., 1985. Temporal stability of spatially measured soil water probability density function. Soil Sci. Soc. Am. J. 49, 822-828.

Vanderlinden, K., Vereecken, H., Hardelauf, H., Herbst, M., Martínez, G., Cosh, M.H. Pachepsky, Y.A., 2012. Temporal stability of soil water contents: a review of data and analyses. Vadose Zone J. 11 (4).

Wang, X.P., Pan, Y.X., Zhang, Y.F., Dou, D.Q., Hu, R., Zhang, H., 2013. Temporal stability analysis of surface and subsurface soil moisture for a transect in artificial revegetation desert area. China J. Hydrol. 507, 100-109.

Williams, C.J., McNamara, J.P., Chandler, D.G., 2009. Controls on the temporal and spatial variability of soil water in a mountainous landscape: the signature of snow and complex terrain. Hydrol. Earth Syst. Sci. 13, 1325-1336.

Zhang, P.P., Shao, M.A., 2013. Temporal stability of surface soil moisture in a desert area of northwestern China. J. Hydrol. 505, 91-101.

Zhao, Y., Peth, S., Wang, X.Y., Lin, H., Horn, R., 2010. Controls of surface soil moisture spatial patterns and their temporal stability in a semi-arid steppe. Hydrol. Process. $24,2507-2519$. 